\title{
Generation and Trapping of a Superelectrophilic Terminal Fluorophosphinidene Complex
}

\author{
Carine Compain, Bruno Donnadieu, François Mathey* \\ UCR-CNRS Joint Research Chemistry Laboratory, Department of Chemistry, \\ University of California Riverside, Riverside, CA 92521-0403

\section{${ }^{1} \mathrm{H}$ and ${ }^{13} \mathrm{C}$ NMR Spectra}




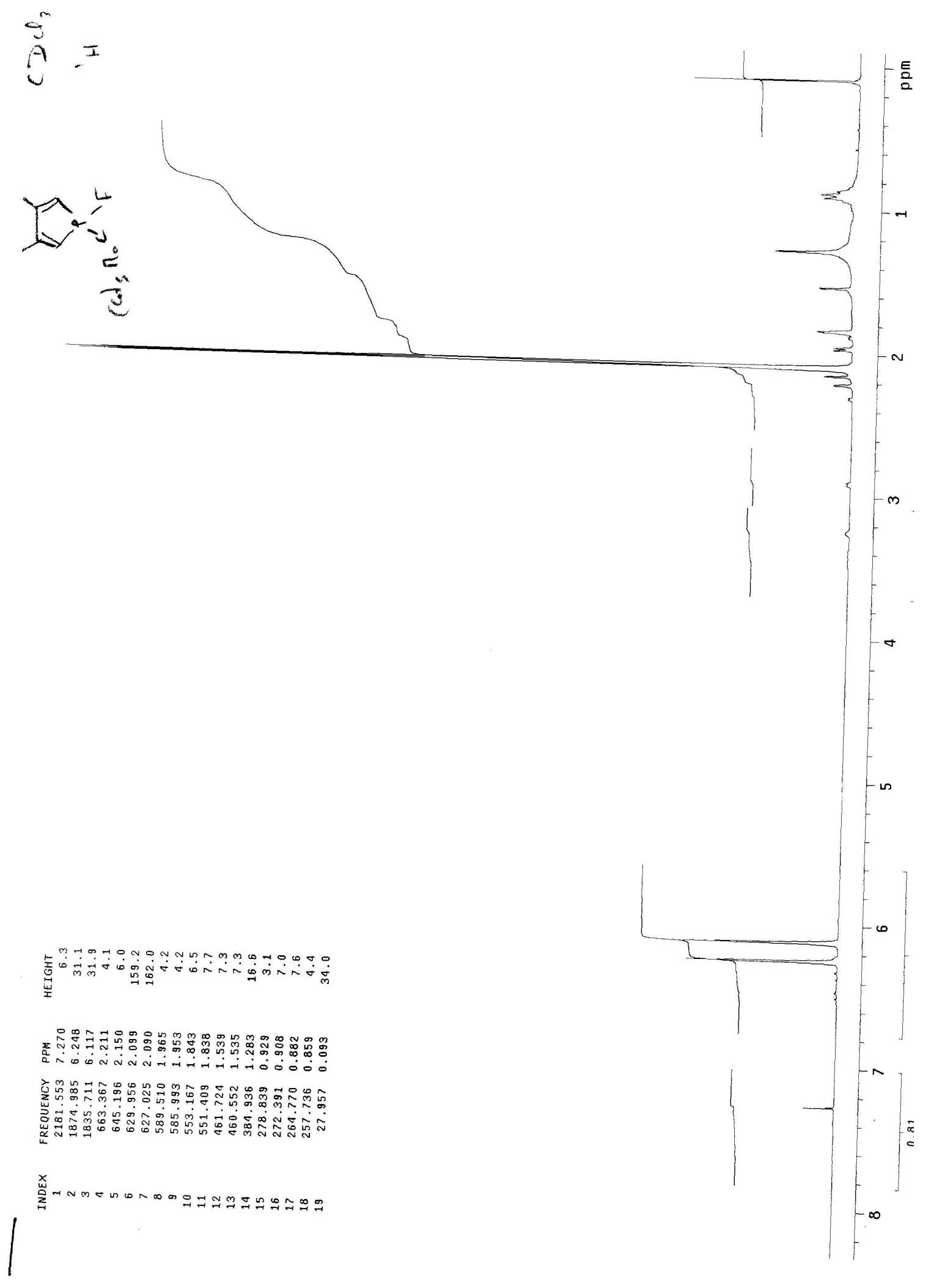

${ }^{1} \mathrm{H}$ NMR spectrum of fluorophosphole 2 


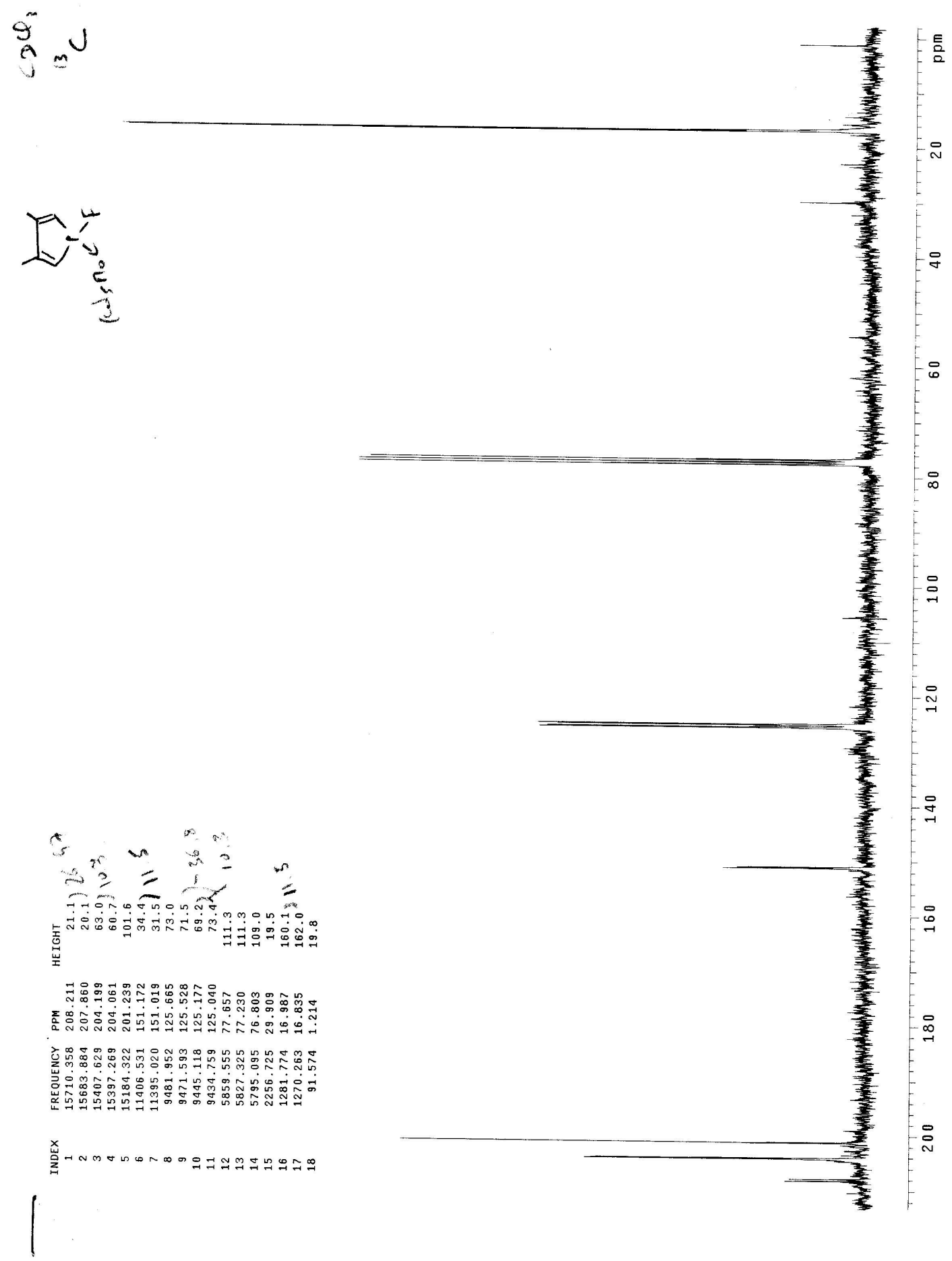

${ }^{13} \mathrm{C}$ NMR spectrum of fluorophosphole 2 


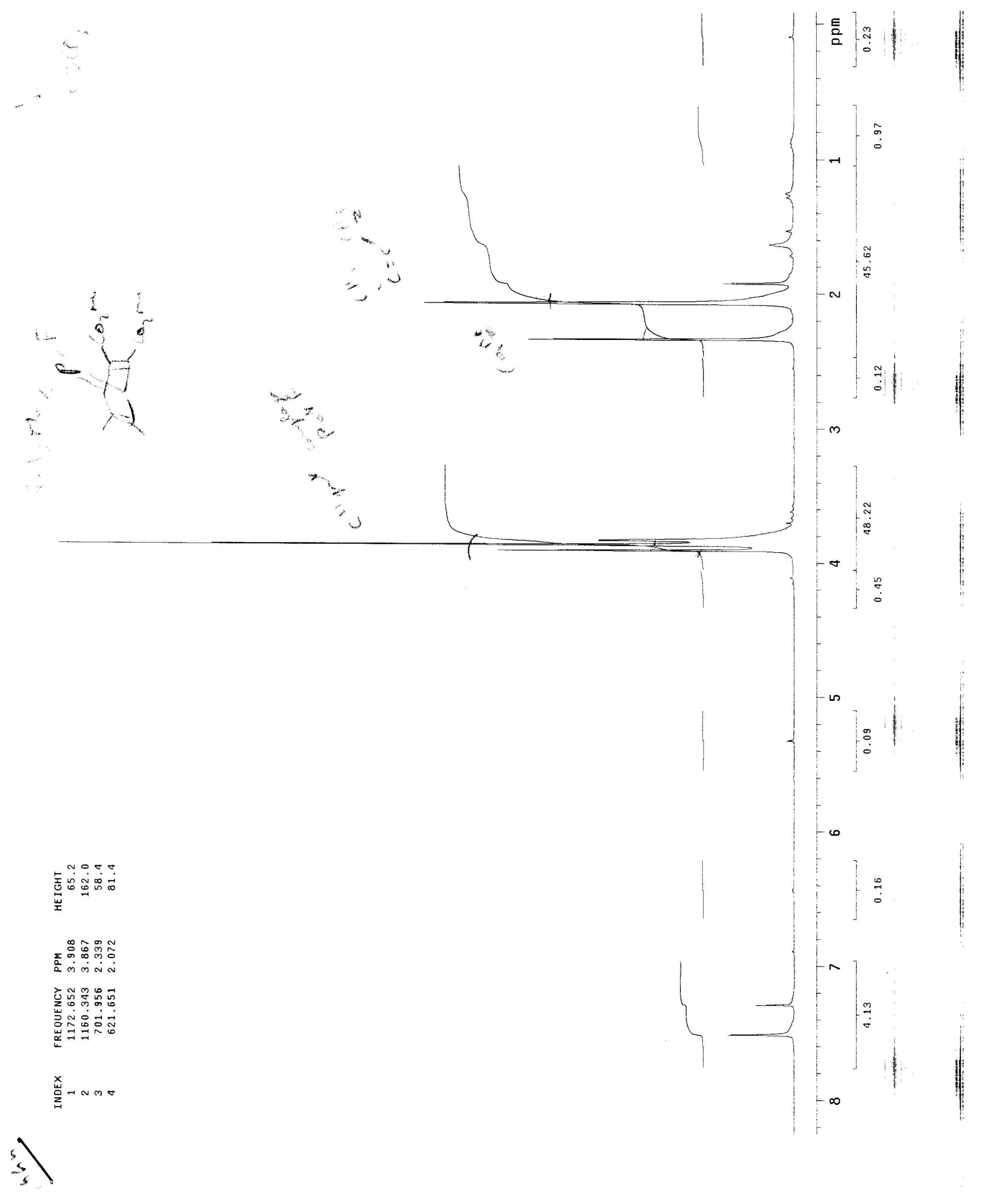

${ }^{1} \mathrm{H}$ NMR spectrum of fluorophosphanorbornadiene 3 


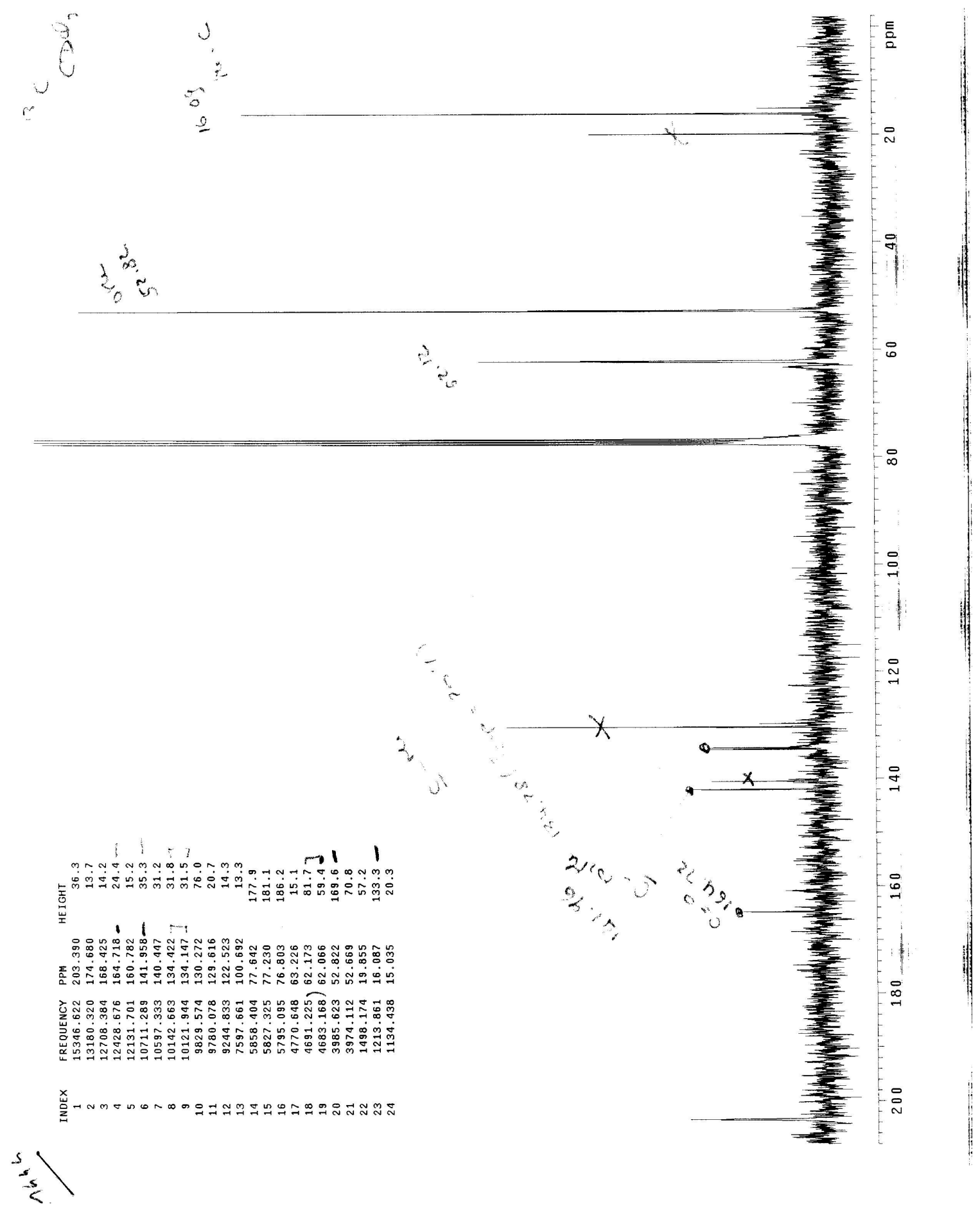

${ }^{13} \mathrm{C}$ NMR spectrum of fluorophosphanorbornadiene 3 


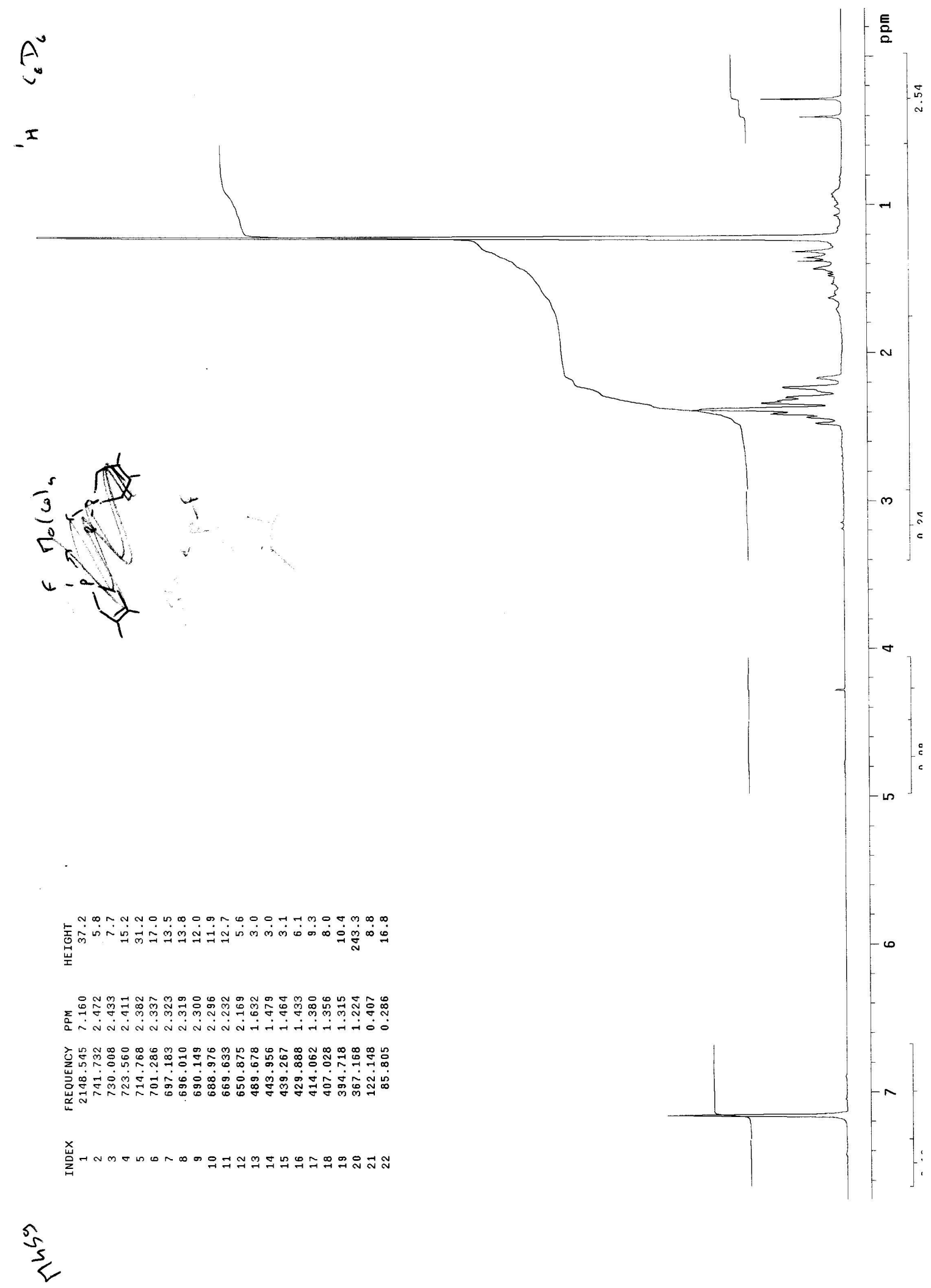

${ }^{1} \mathrm{H}$ NMR spectrum of fluorophospholene 5 


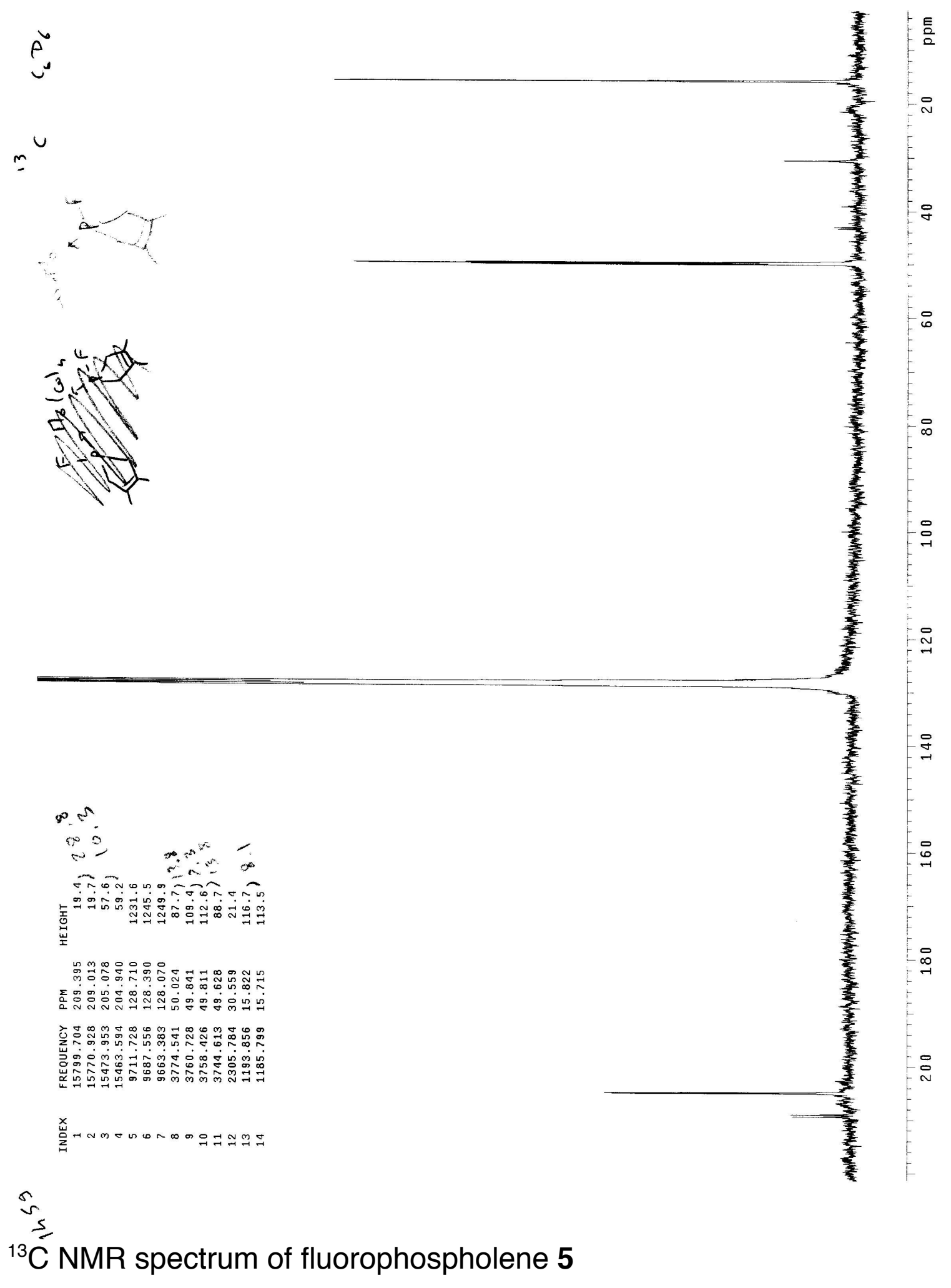




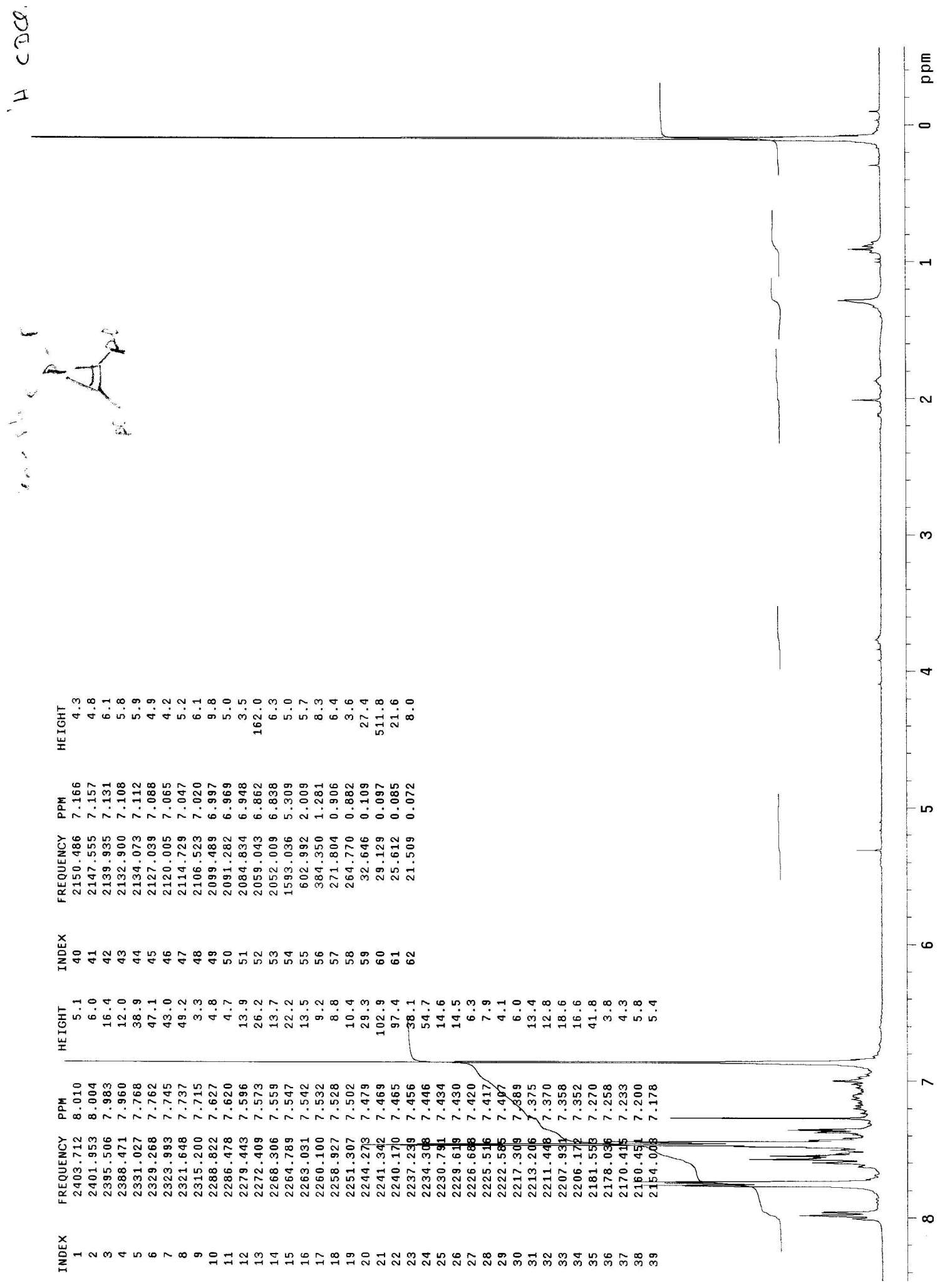

${ }^{1} \mathrm{H}$ NMR spectrum of fluorophosphirene 4 

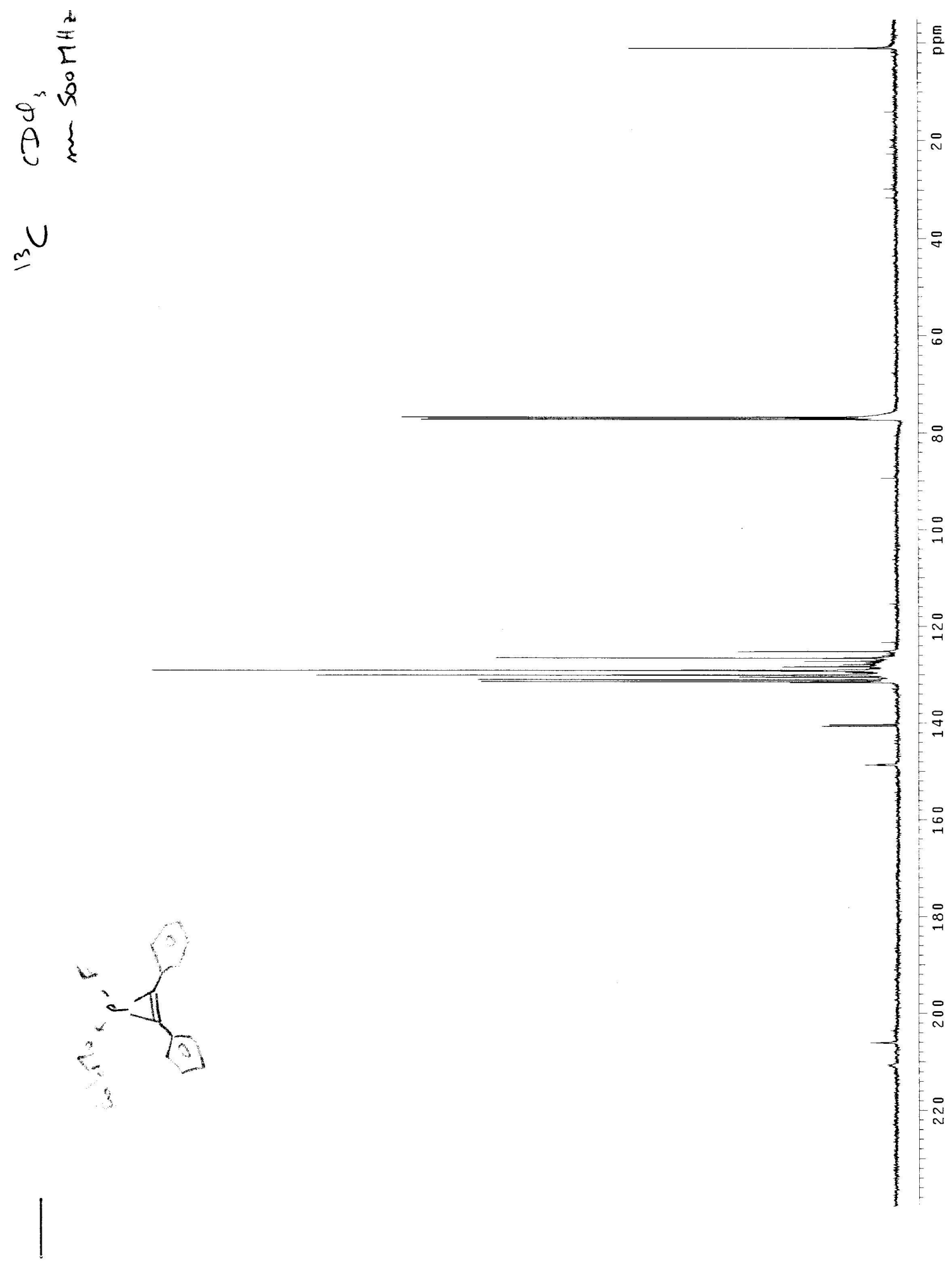

\section{.}

